\title{
Amada pátria idolatrada: um estudo da obra Porque me ufano do meu país, de Affonso Celso (1900)*
}

\section{Beloved and idolized motherland: studying the book Why I am proud of my country, by Affonso Celso (1900)}

\author{
Maria Helena Câmara Bastos**
}

\begin{abstract}
RESUMO
O presente estudo analisa a obra Porque me ufano do mеи país, escrita por Affonso Celso, que se tornou leitura obrigatória nas escolas secundárias brasileiras, tendo várias edições e traduções, transformando-se em uma verdadeira cartilha de nacionalidade. Pode ser considerado um livro de leitura com função moralizadora e intenção educativa, cívica, patriótica e social, um pequeno manual de educação cívica. Essa obra constitui uma unidade discursiva, produtora de ordenamento, de afirmação de distâncias, de divisões (CHARTIER, 1990, p. 28), representativa dos valores da ilustração brasileira quanto ao projeto pedagógico republicano de formação do novo homem para o novo regime: crença ilustrada nas virtudes da instrução moral e cívica, como forma de manter a ordem social e fortalecer o caráter nacional, no período da Primeira República. Nesse período, a educação moral, cívica e religiosa tornou-se o eixo das preocupações para os que almejavam o perene controle das relações e das estruturas sociais, como forma capaz de regenerar o país. A obra não é um exemplo isolado, insere-se na extensa produção de
\end{abstract}

* Este estudo integra a linha de pesquisa "Educação brasileira e cultura escolar: análise das idéias pedagógicas e das práticas educativas e escolares".

** Doutora em História e Filosofia da Educação, Professora no Programa de PósGraduação em Educação da Pontifícia Universidade Católica-RS; Professora Titular em História da Educação no PPGEDU/UFRGS, Pesquisadora do CNPq. mbastos.voy@zaz.com.br 
manuais de "história pátria" que circularam nas primeiras décadas do século $\mathrm{XX}$, com a função de fortalecer a identidade nacional.

Palavras-chave: educação brasileira, Primeira República, leituras de formação.

\begin{abstract}
This study analyzes the book Why I am proud of my country, by Affonso Celso which was a compulsory reading for high school students for many years. This book had many translations and editions and was considered a guide to patriotism for its moralizing function and educative, civic, patriotic, and social intentions. It establishes a discursive unity that "produces order, asserts distances and divisions" (CHARTIER, 1990, p. 28), which represented the values of the Brazilian intelligentsia concerning to the republican pedagogic project of building a new man for a new regime. During the First Republic, such beliefs were represented by the virtues of moral and civic instruction as a means of keeping the social order and fortifying the national character. At that period, moral, civic and religious education became the main concern for those who wanted to control social relations and structures thus regenerating the Nation. This book is inserted in an extensive list of "motherland history" manuals which were available during the first decades of the XX Century and had the objective of strengthening the national identity.
\end{abstract}

Key-wods: Brazilian education, First Republic, readings for formation.

\title{
Introdução
}

O presente estudo pretende analisar a obra Porque me ufano do meu país, escrita por Affonso Celso, que se tornou leitura obrigatória nas escolas secundárias brasileiras, ${ }^{1}$ tendo várias edições e traduções, transformando-se em uma verdadeira cartilha de nacionalidade, ${ }^{2}$ Pode ser considerado

1 Sobre o livro escolar, ver CHOPPIN, A. O Historiador e o livro escolar. Revista História da Educação, Pelotas, v. 6, n. 11, abr. 2002.

2 Para ZILBERMAN e LAJOLO (1986), o início da literatura infantil e juvenil brasileira, no final do século XIX, foi marcado pelo transplante de temas e textos europeus adaptados à linguagem brasileira, com a missão formadora e patriótica. Desde as traduções dos 
um livro educador (CHARTIER; HÉBRARD, 1995), com função moralizadora e intenção educativa, cívica, patriótica e social, um pequeno manual de educação cívica. Sua obra não é um exemplo isolado, insere-se na extensa produção de manuais de "história pátria" que circularam nas primeiras décadas do século XX, com a função de fortalecer a identidade nacional.

Acreditamos que essa obra constitui uma unidade discursiva, produtora de ordenamento, de afirmação de distâncias, de divisões (CHARTIER, 1990, p. 28), representativa dos valores da ilustração brasileira ${ }^{3}$ quanto ao projeto pedagógico republicano de formação do novo homem para o novo regime: crença ilustrada nas virtudes da instrução moral e cívica, como forma de manter a ordem social e fortalecer o caráter nacional, no período da Primeira República. Nesse período, a educação moral, cívica e religiosa tornou-se o eixo das preocupações para os que almejavam o perene controle das relações e das estruturas sociais como forma capaz de regenerar o país. (KUHLMAnN, 1996, p. 228)

José Veríssimo, em A Educação Nacional (1890), denunciava a "pobreza do nosso sentimento nacional devido a não havermos jamais pensado

Contos seletos das Mil e uma Noites, As Aventuras do Barão de Münchhausen, Robison Crusoé, Coração, e as versões abrasileiradas de textos de Perrault, Grimm e Andersen, a literatura infantil lança mão, para arregimentação de seu público, do culto cívíco e do patriotismo como pretexto legitimador. Le tour de la France par deux garçons (1877), de G. Bruno, e Cuore (1886), De Amicis, parecem constituir matrizes inspiradoras de obras que transformaram-se em verdadeiras cartilhas de nacionalidade, como Através do Brasil (1910), de Olavo Bilac e Manoel Bonfim, Porque me ufano do meu País (1901), de Afonso Celso, e outros tantos. O fortalecimento da escola, nas primeiras décadas republicanas, e as campanhas cívicas em prol da modernização da imagem do país favoreceram o desenvolvimento da literatura infantil brasileira e o seu lastro ideologicamente conservador.

3 Affonso Celso pode ser considerado um representante da elite ilustrada brasileira, conforme nos explicita BARROS (1959, p. 108): “o tipo liberal é o tipo dominante da ilustração brasileira. Representativo das principais exigências explícitas da nação, desejando substituir o país oficial pelo país real, tal como o interpretava, a história dos fins do império é, ao mesmo tempo, a história de suas sucessivas conquistas. A ilustração brasileira caracteriza-se, antes de tudo, pelo liberalismo triunfante. Não nos referimos, aqui, exclusivamente, ao liberalismo clássico: embora com diversos fundamentos teóricos, liberais clássicos e cientificistas formulam, geralmente, as mesmas reivindicações. O "cientificismo" ilustrado virá, aliás, reforçar as exigências liberais, trazendo-lhes, freqüentemente, novos e poderosos argumentos. A história da ilustração brasileira chega, assim, a confundir-se com a história do liberalismo nacional, em que pesem as múltiplas e diversas orientações, com o seu esforço civilizador, com o seu trabalho para fazer do Brasil um país, não só cronológica, mas realmente uma nação do século XIX". 
em ter educação nacional". Como solução para esse problema sugere a generalização da educação cívica em toda a instrução dada na escola, como condição fundamental à formação da cultura moral e intelectual. Para o autor, uma educação "para ser nacional precisa que inspire o sentimento de Pátria e que a dirija à um fim patriótico". O fortalecimento do sentimento nacional exigia, também, a educação do caráter, entendida como educação moral, preceitos, regras, exemplos, conselhos, comentários morais de fatos da vida escolar e da história; e "educação física - que enrijece o corpo e solidifica a saúde". Para ele, a "educação do caráter" era "indispensável elemento da nossa educação nacional, deveria ter por fim combater em todos nós tudo o que deprime o nosso caráter, desenvolvendo ao mesmo tempo as qualidades contrárias". Nessa perspectiva, envolvia a "educação da vontade e o desenvolvimento do espírito de disciplina, de simpatia, de solidariedade", destacando como responsáveis por essa missão: a família, a escola, a sociedade, as religiões, a política, a literatura, a ciência e a arte.

Considerava, ainda, a literatura e a leitura importantes dispositivos para a educação cívica e moral. Ao assinalar a ausência de uma cultura cívica assim como moral, acusava o livro de leitura - a mola real do ensino - como o grande responsável por essa situação. Sugeria como uma das mais necessárias reformas a do livro de leitura: "cumpre que ele seja brasileiro, não só feito por brasileiros, que não é o mais importante, mas brasileiro pelos assuntos, pelo espírito, pelos autores traslados, pelos poetas reproduzidos e pelo sentimento nacional que anime." A ênfase da sua argumentação recaía no que considerava "a lacuna fundamental da nossa educação pública: a ausência de um ideal - o sentimento nacional”, pois considerava o sentimento nacional o elo mais sólido da nacionalidade e o mais certo estímulo aos cidadãos.

Nesse contexto, podemos situar a contribuição de Affonso Celso, que objetivava, entre seus ensinamentos, dar destaque à brasilidade, ao patriotismo. Ao explicar para quem e para que foi composto o opúsculo, destacou que desejava que o leitor "consagreis sempre ilimitado amor à região onde nascestes, servindo-a com dedicação absoluta, destinando-se o melhor da vossa inteligência, os primores do vosso sentimento, o mais fecundo da vossa atividade, - dispostos a quaisquer sacrifícios por ela, inclusive o da vida."

valadẽo (1955, p. 49), exaltando o livro Porque me ufano do meu país, afirma que o mesmo supria um vazio na literatura nacional e o caracteriza como 
...esse hino vibrante, que logo aparece, a um só tempo erguido à grandeza moral e à grandeza material do Brasil, e onde o exagero de que o increpam é atenuado pela reação que se impunha, contra um certo descaso pelo que era da terra, uma certa admiração única pelo que vinha de fora, que infelizmente ia lavrando entre nós, quando explicado não fosse pelo nobre transporte do amor à Pátria, amor que ninguém mais alto cultivou do que ele...

Para MARTins (1978, p. 147), o ufanismo não é um fenômeno exclusivamente nacional e tampouco foi inaugurado por Affonso Celso. ${ }^{4} \mathrm{Consi-}$ dera que o autor apenas criou a terminologia de uma atitude mental em que as grandes nações nada se distinguem das pequenas. $\mathrm{O}$ seu livro é apenas mais um balanço psicológico da nacionalidade, comparável, em seu projeto, ao Brasil em 1899, de Santana Néri, ou o Livro do centenário. Martins pergunta-se: "depois de quatro séculos de existência, podia o Brasil justificar a sua existência? e, se o passado justificasse por si mesmo, seria garantia suficiente para o futuro?". Para ele, foram essas as respostas que Affonso Celso procurou e que formulou na síntese da obra Porque me ufano do meu país.

\section{Conde Affonso Celso (1860-1938): chefe venerável do naciona- lismo brasileiro ${ }^{5}$}

Para Bourdieu (1996),

...o intelectual está situado histórica e socialmente, seja na medida em que forma parte de um campo intelectual, o qual por referência a seu projeto

4 Para Martins, Nísia Floresta inaugura o gênero ufanista. Sobre sua obra, ver PALHARES-BURKE, M. L. G. Nísia Floresta. O Carapuceiro e outros ensaios de tradição cultural. São Paulo: Hucitec, 1995; DUARTE, C. L. Nísia Floresta: vida e obra. Natal: Ed.UFRN, 1995.

5 A expressão é de Wilson Martins. 
criador se define e se integra, e/ou ainda, na medida em que é contemporâneo daqueles com os quais se comunica e aos quais se dirige com sua obra, recorrendo implicitamente a todo um código que tem em comum com eles - temas e problemas na ordem do dia, formas de raciocinar, formas de percepção, etc. Suas eleições intelectuais e artísticas mais conscientes estão sempre orientadas pela sua cultura e gosto, interiorizações da cultura objetiva de uma sociedade, de uma época ou de uma classe.

Nessa perspectiva, devemos situar o contexto de ação de Affonso Celso no "ocaso" do Império e primeiras décadas da República brasileira, momentos de significativa confluência de tendências, idéias e propostas político-sociais. Sua biografia nos ajuda a compreender sua trajetória e obra, enquanto portadora de uma história onde se entrecruzam os fios da vida e os fios da obra. ${ }^{6}$ Sua atuação deve ser enfocada na confluência de uma história ao mesmo tempo intelectual, social e política localizada, mas não desligada de outras de seu tempo, dada a circulação cultural e o cosmopolitismo que caracterizam a época.

Affonso Celso de Assis Figueiredo Júnior nasceu em Ouro Preto, em 1860, filho primogênito do Visconde de Ouro Preto ${ }^{7}$ e de Dona Francisca de Paula Martins de Toledo. Formou-se na Faculdade de Direito de São Paulo,

6 A idéia de autor de FOUCAULT (1997, p. 21) nos ajuda a ampliar a compreensão de sujeito histórico. Para ele, "o nome do autor não é um nome próprio como qualquer outro, mas antes um instrumento de classificação de textos e um protocolo de relação entre eles ou de diferenciação face a outros, que caracteriza um modo particular de existência do discurso, assinalando o respectivo estatuto numa cultura dada". Assim, é importante a análise histórico-sociológica da personagem do autor, sua relação com a obra, sua singularidade, o modo de ser do discurso. Foucault vê o autor como um fundador de discursividade, assim a função do autor é característica do modo de existência, de circulação e de funcionamento de alguns discursos no interior de uma sociedade. Nesta perspectiva, considera fundamental a "biografia do autor, da delimitação da sua perspectiva individual, da análise da sua origem social ou da sua posição de classe, da revelação do seu projeto individual".

7 Affonso Celso de Assis Figueiredo. Visconde de Ouro Prêto (1836-1912). Político com significativa atuação durante o Segundo Império, exilando-se na Itália e em Paris, após a proclamação da República, retornando somente em 1891. Pertenceu ao partido Liberal, monarquista, fundador do Tribuna Liberal. Escreveu as obras Idéias sobre a Instrução Primária e Secundária. Sugestões preciosas em torno do Congresso de Instrução, no Rio de Janeiro, a realizar-se em 1882, Reforma das Faculdades de Direito, A Marinha de Outrora, Década Republicana (1899). 
defendendo a tese Direito de Revolução. Filiou-se ao Partido Liberal, foi defensor da abolição da escravatura e do regime republicano, ao contrário de seu pai, monarquista. Mais tarde, ficou solidário com o pai, quando este assumiu a Presidência do Conselho de Ministros, em agosto de 1889. Foi eleito deputado com apenas 22 anos, ocupando o cargo por quatro vezes consecutivas até 1903, quando recusou-se a voltar à Câmara numa resistência passiva à República, que sublimaria no culto do passado imperial, praticado com paixão.

Exerceu inúmeras funções como orador, escritor, poeta, jornalista, historiador, professor. Proferiu conferências nas célebres "Conferências da Glória"; foi professor e diretor da Faculdade de Direito de São Paulo por longos anos; reitor da Universidade do Rio de Janeiro; diretor do Departamento Nacional de Ensino, por 25 anos; em 1892, associou-se ao Instituto Histórico e Geográfico Brasileiro, tendo sido presidente por muitos anos; foi um dos fundadores da Academia Brasileira de Letras. Estimulou a criação da Academia de Altos Estudos e, posteriormente, da Faculdade de Filosofia e Letras do IHGB (1916-1921). ${ }^{8}$ Presidiu a "Ação Social Nacionalista", durante o período de 1919 a 1923, marcado pela ostensiva campanha patriótica.

Foi autor de inúmeras obras literárias: Um capricho do Doutor $O x$, tradução de Julio Verne, em 1874; Prelúdios, poesias (1875); Devaneios, poesias (1877); Telas sonantes, poesias (1879); Poemetos (1880); O Imperador no Exílio (Magalhães, 1893); Minha Filha (1893); Lampejos sacros (poemas); Mês do rosário (poemas); Notas e ficções (Garnier, 1894); Lupe, romance com um capítulo intitulado "Salve, Brasil" (1894); Rimas de outrora (1894); Vultos e fatos (1892, quarta edição: 1896); Aos monarquistas (1895); Guerrilhas (1895); O Assassinato do Coronel Gentil de Castro. Subsídios para a história do regime republicano no Brasil (1897; 1929); Giovannina, drama (1896); Imitação de Cristo, em versos (1898; 1914); Um invejado (1894-95); Biografia de José Vieira Couto Magalhães (1898); Trovas de Hespanha (1904); Oito anos de Parlamento, suas memórias como deputado (Melhoramentos, 1901); As aventuras de Manuel (1903); Poesias escolhidas (1904); O Visconde de Ouro Prêto - excertos biográficos

8 Sobre essas iniciativas do IHGB, ver GUIMARÃES, L. M. P. A experiência pioneira da Academia de Altos estudos: Faculdade de Filosofia e Letras do Instituto Histórico e Geográfico Brasileiro (1916-1921). Teias, Rio de Janeiro, ano 1, n. 1, p. 38-45, jan./jun. 2000 . 
(Globo, 1935); Poder pessoal de D. Pedro II. Colaborou em inúmeros periódicos: Tribuna Liberal (SP); Gazeta de Sorocaba (SP); Tribuna Liberal (RJ); Brasil (RJ); Revista Brasileira, periódico de intensa reafirmação nacional; e outros. Durante anos, colaborou com o Jornal do Brasil, onde criou a seção "Cotas ao Caos".

\section{Porque me ufano do meu país. Right or wrong, my country ${ }^{9}$}

O livro é dedicado aos filhos - Affonso Celso de Ouro Preto, Carlos Celso de Ouro Preto e à memória de João Paulo de Ouro Preto ${ }^{10}$ - e escrito para "celebrar a nossa Pátria o quarto centenário do seu descobrimento". Foi concluído em Petrópolis, Rio de Janeiro, no dia 8 de setembro de 1900. Desde a primeira edição, consta abaixo do título o sugestivo subtítulo right or wrong, my country, dístico que é a síntese mais perfeita do ufanismo nas tradições anglo-saxônicas e em língua inglesa (MARTINs, 1978, p. 148).

A editora Laemmert publicou a primeira edição em 1901, a qual esgotou-se em alguns meses, fazendo nova edição no mesmo ano. Foi editado em tamanho in-16, com 204 páginas. A partir dessa edição, passou a ser publicado pela livraria Garnier ${ }^{11}$ (Rio de Janeiro/Paris), com o mesmo número de páginas, mas in-18 (quinta edição, 1912; sétima edição, 1915; décima edição, 1926; décima primeira edição, 1937; décima segunda edição, pela F. Briguet, 1943). Na décima edição, de 1926, a obra foi revista e atualizada, e compôs a "Coleção dos Autores Célebres da Literatura Brasileira". Essa edição, em tamanho in-12, tem uma tiragem de 10.000 exemplares numerados, o que permite verificar o grande sucesso da obra vinte e cinco anos depois.

9 O exemplar examinado é da sexta edição revista, impresso na França pela Tipografia Lainé (Chartres). Pertenceu a Lino Corrêa e foi comprado na Livraria Popular de Alcides Costa, de Porto Alegre. Várias marcas a lápis no livro indicam o destaque que o leitor deu às idéias do autor.

$10 \mathrm{Na}$ primeira edição não constava na dedicatória o nome desse filho, falecido com 4 anos de idade.

11 Sobre a Garnier no Brasil e França, consultar HALLEWEL, L. O livro no Brasil (sua história). São Paulo: T. A. Queiroz, 1985; MOLLIER, J.-Y. L'Argent et les Lettres. Histoire du capitalisme d'édition (1880-1920). Paris: Fayard, 1988. 
O seu sucesso também pode ser aquilatado pelas inúmeras traduções - francês, alemão, inglês e italiano. Para o francês, foi traduzido por M. C. (Condessa de Serra Negra), com o título Pourquoi je m'enorgueillie de mon pays, com uma notícia preliminar da tradutora sobre o autor e com inúmeras fotografias, as quais não constam na edição brasileira. Foi editado pela Garnier em 1912, com 276 páginas, com a seguinte observação petit livre de vulgarisation qui renferme une documentation assez sûre. A tradução para o alemão foi feita por Herman Faulhaber, com o título Warum bin ich stolz auf mein Vaterland?, tendo sua terceira edição em1910 (Berlim, O. Brandstetter). A obra não apresenta bibliografia, mas na última página consta uma nota em que o autor esclarece ao leitor as fontes utilizadas "Os principais fatos e observações componentes deste opúsculo, colheuas o autor nos livros de Elisée Reclus, Robert Southey, Porto Seguro, Wappoeus, João Francisco Lisboa, Barão de Rio Branco, João Ribeiro e outros que escreveram sobre o Brasil". Complementa a nota com a observação de que "nem sempre foram citados nomes e obras, com indicações precisas, por se tratar de ligeiro trabalho de vulgarização".

A leitura da obra permite ainda identificar outros autores e leituras realizadas: Américo Vespúcio; Pero Vaz de Caminha; Padre Simão de Vasconcelos - Notícias Curiosas; Rocha Pitta - História da América Portuguesa; Simão Estácio da Silveira; Alexandre Humboldt; Maurício Lamberg; Gonçalves Dias; Augusto Fausto de Souza - A Bahia do Rio de Janeiro, sua história e descrição de suas riquezas; Agassiz; Pieter Wilhen Lund; Victor Hugo; Oliveira Martins; Oliveira Viana; Ernest Renan.

A obra está dividida em 42 pequenos capítulos, os quais procuram demonstrar a superioridade brasileira, a partir de onze argumentos e fatos: grandeza territorial, beleza física, riqueza, variedade e amenidade do clima, ausência de calamidades, excelência dos elementos que entraram na formação do tipo nacional, não ter sido povoado por degradados, os nobres predicados do caráter nacional, nunca sofreu humilhação e nunca foi vencido, procedimento cavalheiresco e digno com os outros, as glórias a colher a sua história.

No capítulo 40, o autor faz um resumo das grandezas do Brasil, em que evidencia o espírito otimista e entusiástico que o anima a provar que ser brasileiro significa distinção e vantagem, incitando o leitor a propagá-los, cultivá-los e engrandecer o amor pelo país, mote da obra. Para o autor, 
...o Brasil constitui um dos mais vastos países da terra, capaz de conter toda a população nela existente; reúne imensas vantagens a essa grandeza territorial, quais a situação geográfica, a homogeneidade material e moral, o progresso constante; é belíssimo; possui riquezas incalculáveis; goza de perpétua primavera, sem jamais conhecer temperaturas extremas; não sofre calamidades que costumam afligir a humanidade; resulta a sua população da fusão de três raças dignas e valorosas raças; bom, pacífico, ordeiro, serviçal, sensível, sem preconceitos, não deturpa o caráter desse povo nenhum vício que lhe seja peculiar, ou defeito insusceptível de correção; nunca sofreu humilhações, nunca fez mal, nunca perdeu uma polegada do seu solo, nunca foi vencido, antes tem vencido poderosas nações; sempre procedeu honesta e cavalheiramente para com os outros povos, livrando, com absoluta abnegação, de odiosas tiranias seus vizinhos mais fracos; cheio de curiosidades naturais, depara elevadas glórias a quem estudar e amar; na sua história, relacionada com os mais notáveis acontecimentos da espécie humana, escasseiam guerras civis e efusões de sangue, sobejando feitos heróicos, formosas legendas, preclaras figuras, luminosos exemplos; primeiro país autônomo da América Latina, segundo do Novo Mundo, sempre manifestou espírito de independência, desfrutou liberdades desconhecidas em outras nações, mostrou-se apto para todas as melhorias, produziu representantes distintos em qualquer ramos de atividade social, resolveu com calma e sensatez, à luz do direito, a mór parte das suas questões, acolheu carinhosamente quem quer que o procurasse, aumentou sem cessar.

Após essa extensa lista de fatos, que comprovam a superioridade brasileira, o autor conclui que "o brasileiro passa dias mais felizes, dias mais tranqüilos, mais risonhos, mais esperançosos que o alemão, o francês, o inglês".

Para Affonso Celso, os traços principais do nosso caráter nacional seriam:

...sentimento de independência, levado até à indisciplina; hospitalidade; afeição à ordem, à paz, ao melhoramento; paciência, resignação; doçura, longanimidade, desinteresse; escrúpulo no cumprimento das obrigações contraídas; espírito extremo de caridade; acessibilidade, que degenera, às vezes, em imitação do estrangeiro; tolerância, ausência de preconceitos de raça, cor, religião, posição; honradez no desempenho de funções públicas ou particulares. 
Para reforçar suas idéias, citas as palavras balizadas de Victor Hugo sobre os brasileiros: "sois homens de sentimentos elevados, sois uma generosa nação. Tendes a dupla vantagem de uma terra virgem e de uma história antiga. Um grande passado histórico vos liga ao continente civilizador. Reunis a luz da Europa ao sol da América".

$\mathrm{O}$ autor não faz referência às mazelas que afligem o Brasil: analfabetismo, epidemias, catástrofes, escravidão etc. Por exemplo, quando se refere à escravidão, relativiza suas graves consequiências e procura demonstrar o processo pacífico, natural, em pé de igualdade que foi a incorporação da população escrava "muitos continuando a trabalhar, sem ressentimentos recíprocos, ao lado dos seus ex-donos". O quadro trágico da realidade nacional é pintado com muitas cores, nuançado ao leitor, através da significativa questão final: "em que ponto do globo, em que página da história se registra uma revolução social, econômica e política desta magnitude e alcance, executada de maneira tão nobre?". (p. 187)

Quanto ao futuro, o autor é de um otimismo magnífico, excessivo: "viveremos, cresceremos, prosperaremos. A educação, o aperfeiçoamento, hão de vir. Somos ainda uma aurora. Chegaremos necessariamente ao brilho e ao calor do meio dia. (...) Cumpre que a esperança se torne entre nós, não uma virtude, mas estrita obrigação cívica" (p. 198). Apesar dessa exaltação, o autor não deixa de sinalizar ao leitor os perigos que ameaçam o Brasil: maus governos; separação do território nacional em vários Estados; intervenção nos seus negócios de alguma potência estrangeira; problemas relativos à afirmação de uma república nacional e internacionalmente reconhecida. Conclui esse capítulo citando Ernest Renan - "o que une e constitui as nações é o sentimento do passado, a posse em comum de um rico legado de tradições, o desejo de viver juntos e a incessante vontade de manter e continuar a fazer valer indivisa a herança recebida" -, reforçando a premissa "depende simplesmente dos brasileiros unir e constituir assim o Brasil”. (p. 195) 


\section{Concluindo}

Para CHARTIER (2001, p. 135), a produção de um conhecimento é constitutiva de uma intencionalidade histórica. Nessa perspectiva, a intenção de Affonso Celso insere-se historicamente em um momento de exaltação da nação brasileira, que marca parte da produção intelectual da Primeira República, em constante busca ou afirmação de uma identidade nacional. Porque me ufano do meu país é, com Através do Brasil (1910), de Olavo Bilac e Manoel Bonfim, Saudade (1917), de Thales de Andrade, um exemplar da literatura infanto-juvenil voltada a exaltar a nacionalidade brasileira, para gerações de estudantes de nossas escolas, fazendo a apologia do país de futuro, de progresso, de ordem, sem conflitos, com miscigenação. ${ }^{12}$

Também nesse período, produziram-se obras que acentuavam uma visão negativa do país - de um país incompreensível, indefinível, invertido e paradoxal -, como a de Fradique Mendes - História do Brasil pelo método confuso (1922) (saliBA, 1998, p. 298). Ou a obra de Martins de Almeida - O Brasil Errante -, considerada um ensaísmo modernista em reação deliberada e sardônica contra o ufanismo de Affonso Celso; o pessimismo otimista de Paulo Prado - Retrato do Brasil (1928) - e o otimismo pessimista de Alberto Torres. Ainda em 1955, a obra de Affonso Celso foi mote para Millôr Fernandes fazer a peça Um elefante no caos ou Jornal do Brasil ou, sobretudo, Porque me ufano do meu país. ${ }^{13}$

A história da obra e das diferentes modalidades de sua apropriação ${ }^{14}-$ o "mundo do texto" e o "mundo do leitor" - permitem interpretar os discur-

12 NAXARA (1998, p. 17) afirma que a passagem do século XIX para o XX constitui um momento privilegiado para o estudo do imaginário sobre a população brasileira, na constituição de uma identidade da nação, identidade do povo brasileiro.

13 Millôr FERNANDES (1978) afirma que essa peça foi "escrita em 1955, com o intuito básico de fazer uma espécie de anti-Conde Affonso Celso - o criador do ufanismo à medida em que praticamente todos os meus personagens são impuros, tontos, corruptos, marginais ou marginalizados, mesmo quando funcionando dentro de uma aparente normalidade." A peça foi premiada pela Associação Brasileira de Críticos Teatrais, em 1960. Em 1971, foi censurada pelo regime militar.

14 "Pensar as apropriações culturais permite também que não se considerem totalmente eficazes e radicalmente aculturantes os textos ou as palavras que pretendem moldar os pensamentos e as condutas. As práticas que deles se apoderam são sempre criadoras de usos ou de representaçõoes que não são de forma alguma redutíveis à vontade dos produtores de 
sos em circulação e sua relação com o mundo social (CHARTIER, 2001). Nessa perspectiva, esse estudo necessita ainda tratar da adoção e apropriação da obra de Affonso Celso. Com essa intenção, procuramos em livros de memórias pistas que nos permitissem verificar o significado de sua leitura, a partir de sua inclusão nas recordações que marcaram os anos na escola. Isto é, verificar o impacto causado em ilustres leitores, ou seja, "face a um texto, historicamente é produzido um sentido e diferenciadamente construída uma significação". Também buscamos apresentar o poder de influência do conteúdo do livro sobre o leitor, ou seja, a aceitação dos fatos e situações representadas no livro.

Uma primeira pista encontramos nas Histórias de leituras de Paulo RANGEL (2000, p. 113), quando afirma que:

Eu me lembro de, nessa época, a gente ter de decorar ou estudar na escola os livros considerados de apoio escolar ou paradidáticos. Um deles era um poema que ficou famoso, muita gente sabia de cor, mas eu não conseguia decorar, por mais força que fizesse. Era Por que me ufano do meu país, do Conde Afonso Celso, que escreveu também para crianças e jovens. Esse poema era bem representativo da época. Era preciso dizer que o Brasil era o maior país do mundo, que aqui tudo era melhor. Olavo Bilac também falava em patriotismo, em seus livros infantis. Esse patriotismo dizia que era muito bom dormir em berço esplêndido, o que tornava a escola um pouco antipática. Intuitivamente os alunos achavam que estavam sendo conduzidos.

Generoso Ponce Filho (1898-1972), no seu livro O Menino que eu era-memórias (1967, p. 112-113), descreve o seu contato com a obra de Affonso Celso: "Mas em 1908, passando para o Complementar, deslumbrou-nos um livro de leitura diferente - os exemplares novos vindos do Rio de Janeiro, edição da Casa Laemmert. Capa cartonada branca, faixa verde-

discursos e de normas. $\mathrm{O}$ ato de leitura não pode de maneira nenhuma ser anulado no próprio texto, nem nos comportamentos vividos nas interdições e nos preceitos que pretendem regulá-los. A aceitação das mensagens e dos modelos opera-se sempre através de ordenamentos, de desvios, de reempregos singulares que são o objeto fundamental da histórria cultural." CHARTIER, op. cit. p. 137. 
amarela, de alto a baixo. Em azul marinho o título 'Porque me ufano do meu Paiz', de Affonso Celso, nome novo para nós...”. MARTins (1977, v. 5, p. 227) cita as recordações de Andrade Murici, que conta que "fruto do ardor cívico do professor adveio-me a ter ali recebido lições muito especiais daquele ufanismo provindo do livro de Affonso Celso que era, com 'Os Lusíadas'e 'Iracema', de leitura e análise obrigatória".

Teixeira de Freitas (1939, p. 84), também fala sobre a obra: "Qual de nós, na mocidade, não leu, profundamente comovido, esse pequeno livro e não sentiu a alma impregnada de um sentimento generoso, de um sentimento profundo de amor ao Brasil?" Gastão PERnalva (1938) recorda de umas férias longínquas, em que pôs na mala de viagem o Cuore, de Amicis, ${ }^{15}$ a Volta ao Mundo, de Júlio Verne, as Poesias, de Castro Alves, o Porque me ufano do meu país, de Affonso Celso - "o livro mais patriótico que se tem divulgado no Brasil".

A primeira leitura dessa obra, cem anos depois de sua primeira edição, remete-me ao livro de Diogo mainardi (1998), Contra o Brasil, que faz uma desconstrução dessa história otimista, idealizada e idealista do Brasil. O nacionalismo de Affonso Celso passa uma visão ingênua, romântica, apaixonada, extravagante e irreal da situação brasileira, representativa de uma fantasia de Brasil das elites, na busca de uma identidade nacional espelhada na diferença das qualidades em um universo cultural formado pela importação de cânones estrangeiros.

15 Cf. BASTOS, M. H. C. Educação do caráter nacional: leituras de formação. Revista Educação e Filosofia, Uberlândia, v. 12, n. 23, jan./jun. 1998. 


\section{REFERÊNCIAS}

ALENCAR, J. S. de. Flagrantes da Vida escolar brasileira: final do século XIX e início do XX (relatos autobiográficos). São Paulo: PPGEDU/FEUSP, 1996.

BARROS, R. S. M. de. A ilustração brasileira e a idéia de universidade. São Paulo: FFCL/USP, 1959.

BOURDIEU, P. Campo intelectual y projeto criador. In: HERSCHMANN, M. et al. Missionários do progresso. Rio de Janeiro: Diadorim, 1996.

BOURDIEU, P. A ilusão biográfica. In: FERREIRA, M.; AMADO, J. (Org.). Usos e abusos da História Oral. Rio de Janeiro: Ed. FGV, 1996.

CHARTIER, A.-M.; HÉBRARD, J. Discursos sobre a leitura (1880-1980). São Paulo: Ática, 1995.

CHARTIER, R. Uma crise da história? A história entre narração e conhecimento. In: PESAVENTO, S. (Org.). Fronteiras do milênio. Porto Alegre: Ed. UFRGS, 2001. p. 115140.

CHARTIER, R. A História Cultural: entre práticas e representações. Lisboa: Difel, 1990.

ENCICLOPÉDIA Barsa. v. 1, p. 95.

FERNANDES, M. Um elefante no caos. Porto Alegre: L\&PM, 1978. 127 p.

FORD, J.; WHITTEM, A.; RAPHAEL, M. A tentative bibliography of Braziliam BellesLettres. Cambridge: Harvard University Press, 1931.

FOUCAULT, M. O que é um autor? Lisboa: Passagens, 1997.

HALLEWEL, L. O livro no Brasil (sua história). São Paulo: T. A. Queiroz, 1985.

IHGB. Homenagem à memória do Conde de Affonso Celso. Rio de Janeiro: Imprensa Nacional, 1939.

KUHLMANN JUNIOR, M. As grandes festas didáticas. A educação brasileira e as exposições internacionais. 1862-1922. São Paulo, 1996. Tese (Doutorado) - USP/FFCH.

MAINARDI, D. Contra o Brasil. São Paulo: Cia. das Letras, 1998.

MARTINS, W. História da inteligência brasileira. São Paulo: Cultrix, 1978. v. 4, 5, 6 e 7.

MOLLIER, J.-Y. L'Argent et les Lettres. Histoire du capitalisme d'édition (1880-1920). Paris: Fayard, 1988. 
PONCE FILHO, G. O menino que eu era - memórias. Rio de Janeiro: Livraria Lançadora, 1967.

RANGEL, P. Histórias de leituras. In: GARCIA, P. B.; DAUSTER, T. (Org). Teia de autores. Belo Horizonte: Autêntica, 2000. p. 107-120.

SALIBA, E. T. A dimensão cômica da vida privada na República. In: SEVCENKO, N. (Org.). História da Vida Privada no Brasil. São Paulo: Cia. das Letras, 1998. v. 3.

SOUZA, O. Fantasia de Brasil. As identificações na busca da identidade nacional. São Paulo: Escuta, 1994.

VALADÃO, A. Vultos nacionais. Rio de Janeiro: J. Olympio, 1955.

VERÍSSIMO, J. A educação nacional. Porto Alegre: Mercado Aberto, 1985.

ZILBERMAN, R.; LAJOLO, M. Um Brasil para crianças. Para conhecer a literatura infantil brasileira: histórias, autores e textos. São Paulo: Global, 1986.

Texto recebido em 1 fev. 2002

Texto aprovado em 8 mai. 2002 